\title{
S100A4 promotes invasion and angiogenesis in breast cancer MDA-MB-231 cells by upregulating matrix metalloproteinase-13
}

\author{
Lin Wang ${ }^{1}$, Xingang Wang2 ${ }^{2}$ Yu Liang ${ }^{3}$, Xinying Diao ${ }^{3}$ and Qingfeng Chen ${ }^{2 凶}$ \\ 1Department of Breast and Thyroid Diseases, Tianjin Union Medicine Centre, Tianjin, China; ${ }^{2 B}$ reast Surgery, the Affiliated Hospital of Qingdao \\ Medical College, Qingdao University, Qingdao, R.P.China; ${ }^{3 B r e a s t}$ Surgery, the Second Hospital of Tianjin Medical College, Tianjin, R.P.China
}

\begin{abstract}
S100A4 is a member of the S100 family of calcium-binding proteins that is directly involved in tumor metastasis. In the present study, we examined the potential role of S100A4 in metastasis in breast cancer and its relation with matrix metalloproteinase-13 (MMP-13). Analysis of 100 breast cancer specimens including 50 with and 50 without lymph node metastasis showed a significant upregulation of S100A4 and MMP-13 expression in metastatic breast cancer tissues. Positive immunoreactivity for S100A4 was associated with MMP-13 expression. Overexpression of S100A4 in the MDA-MB-231 breast cancer cell line upregulated MMP13 expression leading to increased cell migration and angiogenesis. SiRNAmediated silencing of S100A4 downregulated MMP13 expression and suppressed cell migration and angiogenesis. Moreover, neutralization of MMP-13 activity with a specific antibody blocked cell migration and angiogenesis in MDA-MB-231/S100A4 cells. In vivo siRNA silencing of S100A4 significantly inhibited lung metastasis in transgenic mice. The present results suggest that the S100A4 gene may control the invasive potential of human breast cancer cells by modulating MMP-13 levels, thus regulating metastasis and angiogenesis in breast tumors. S100A4 could therefore be of value as a biomarker of breast cancer progression and a novel therapeutic target for human breast cancer treatment.
\end{abstract}

Key words: breast cancer; metastasis; S100A4; MMP-13

Received: 29 March, 2012; revised: 03 July, 2012; accepted: 24 October, 2012; available on-line: 16 November, 2012

\section{INTRODUCTION}

S100A4, also known as mts1, p9Ka, FSP1, CAPL, calvasculin, pEL98, metastasin, 18A2, and 42A, was cloned in the 1980s and early 1990s from various cell systems (Garrett et al., 2006). The human S100A4 gene is located in a frequently rearranged gene cluster on chromosome $1 \mathrm{q} 21$ and is composed of four exons, of which the first two are noncoding (Garrett et al., 2006). The 101-amino acid protein has a molecular mass of approximately 11.5 $\mathrm{kDa}$ and is characterized by the presence of two $\mathrm{Ca}^{2+}$ binding EF-hands. Upon $\mathrm{Ca}^{2+}$-binding, S100A4 undergoes a conformational change, forming a hydrophobic pocket essential for the recognition of target proteins (Malashkevich et al., 2008).

A number of studies have demonstrated the involvement of the S100A4 gene product in the promotion of metastasis. Introduction of the S100A4 gene into nonmetastatic tumor cell lines and suppression of its activity in cells with known metastatic potential proved its involvement in metastasis formation (Ford et al., 1995; Maelandsmo et al., 1996; Klingelhöfer et al., 1997; Lloyd et al., 1998; Wang et al., 2006). Furthermore, transgenic mouse models overexpressing the S100A4 gene showed enhanced metastatic activity (Ambartsumian et al., 1996; Levett et al., 2002; Liu et al., 2010). Recent studies showed that S100A4 expression is associated with metastatic breast cancers (Rudland et al., 2000; Ismail et al., 2008), and is upregulated in cancer tissues compared with normal breast tissue, suggesting that S100A4 plays a role in the metastatic phenotype. However, the mechanisms by which S100A4 promotes tumor progression or metastasis have not been elucidated.

Matrix metalloproteinases (MMPs) play an essential role in tumor metastasis and invasion, and several experimental strategies have established an intimate connection between S100A4 and certain members of the MMP family. In a recent study, treatment of mouse endothelial SVEC 4-10 cells with the S100A4 protein caused the transcriptional activation of collagenase 3 (MMP-13) mRNA followed by the subsequent release of the protein from the cells. The resulting enhancement of the proteolytic activity associated with MMP-13 was demonstrated by beta-casein zymography. These findings suggest that S100A4 may induce the synthesis of extracellular matrix (ECM) degrading enzymes resulting in the remodeling of the ECM (Schmidt-Hansen et al., 2004).

In vitro and in vivo models of metastatic breast cancer have provided evidence supporting the direct involvement of S100A4 in tumor progression and metastasis (Simpson et al., 2003; Jenkinson et al., 2004). Clinical evidence suggests that matrix metalloproteinase-13 (MMP13) could be a useful prognostic marker for predicting the development and progression of breast cancer (Zhang et al., 2008).

In the present study, the expressions of S100A4 and MMP-13 and their relationship with breast cancer progression and metastasis were analyzed in vivo and in vitro to gain insight into the mechanisms of S100A4-induced metastatic progression.

\section{MATERIALS AND METHODS}

Tissue sample collection. One-hundred paraffinembedded archival specimens of primary breast cancer from patients with and without lymph node metastasis

e-mail: chendd820@126.com

Abbreviations: DMEM, Dulbecco's Modified Eagle's Medium; ECM, extracellular matrix; MMP-13, matrix metalloproteinase-13; RT-PCR, Reverse transcription polymerase chain reaction. 
( $\mathrm{n}=50$ each) were included in the study. None of the patients had received pretreatment.

Cell culture. MDA-MB-231(MDA-231) human breast cancer cells were purchased from the American Type Culture Collection and cultured in DMEM supplemented with $10 \%$ fetal bovine serum in a humidified $\mathrm{CO}_{2}$ incubator at $37^{\circ} \mathrm{C}$. High expression levels of S100A4 (Matsuuraet al., 2010) and MMP-13 (McKay et al., 2002) have been reported in the MDA-231 cell line.

Immunohistochemistry. Specimens were cut into 4 $\mu \mathrm{m}$ sections and mounted on positively charged slides, incubated for $30 \mathrm{~min}$ at $60^{\circ} \mathrm{C}$, deparaffinized by conventional methods, and washed in Tris-buffered saline buffer. Antigen retrieval was performed for $20 \mathrm{~min}$ in $10 \mathrm{mmol} / \mathrm{L}$ of sodium citrate buffer ( $\mathrm{pH}$ 6.0) heated at $95^{\circ} \mathrm{C}$ in a steamer, followed by cooling for $20 \mathrm{~min}$. After blocking endogenous peroxidase activity with a $3 \%$ aqueous $\mathrm{H}_{2} \mathrm{O}_{2}$ solution for $5 \mathrm{~min}$, sections were incubated in polyclonal anti-S100A4 (1:100, Santa Cruz Biotechnology Inc., Santa Cruz, CA, USA) and anti-MMP-13 (1:150, Santa Cruz) antibodies. The percentage of carcinoma cells with cytoplasmic staining was calculated from two sections of each specimen, 10 fields/section, at $200 \times$ magnification. Specimens were classified into two groups according to the expression of S100A4: specimens with $<1 \%$ S100A4 staining were designated as negative $(-)$ and those with $\geq 1 \%$ were designated as positive $(+)$. For MMP-13, specimens with $<5 \%$ stained cells were designated as negative $(-)$ and those with $\geq 5 \%$ were designated as positive.

siRNA transfection. Pre-designed siRNAs were purchased from Invitrogen. The siRNA targeted sequences were 5'-AACGAGGTGGACT'TCCAAGAG-3' for S100A4, and 5'-AATTCTCCGAACGTGTCTCGT-3' for the non-silencing control siRNA. The siRNAs were transfected into MDA-231 cells using Lipofectamine ${ }^{\mathrm{TM}}$ RNAi Max (Invitrogen) for $48 \mathrm{~h}$ according to the manufacturer's instructions.

Plasmid construction and transfection. The pGEM-S100A4 plasmid was procured from Biovector Science Lab, Inc., and S100A4-cDNA was isolated from pGEM-S100A4 using the BamH I restriction endonuclease. The digested fragment was then ligated into the pcDNA3.1 vector (Invitrogen) previously digested with BamH I and treated with calf intestinal alkaline phosphatase. The resulting construct was verified by direct sequencing. For transfection studies, MDA-231 cells were plated at a density of $1 \times 10^{6}$ cells per well in six-well plates and incubated for $24 \mathrm{~h}$ in complete medium. The cells were then transfected with $2-4 \mu \mathrm{g}$ of the S100A4 construct using Lipofectamine ${ }^{\mathrm{TM}}$. The same amount of empty vector was transfected as a positive control. Dulbecco's Modified Eagle's Medium (DMEM) containing G418 (600 $\mu \mathrm{g} / \mathrm{mL})$ was used for selection of stable transfectants, and DMEM with $300 \mu \mathrm{g} / \mathrm{mL}$ G418 was used for maintenance of the stable transfectants.

Western blotting. Cells were harvested by trypsinization after transfection with the pcDNA3.1-S100A4 plasmid $(24 \mathrm{~h})$ or S100A4 siRNA plasmid (48 h), washed with PBS, and lysed overnight at $-20^{\circ} \mathrm{C}$ in lysis buffer $(20 \mathrm{mmol} / \mathrm{L}$ Tris/ $\mathrm{HCl}, \mathrm{pH} 7.6,100 \mathrm{mmol} / \mathrm{L}$ $\mathrm{NaCl}, 20 \mathrm{mmol} / \mathrm{L} \mathrm{KCl}, 1.5 \mathrm{mmol} / \mathrm{L} \mathrm{MgCl}_{2}$ and $0.5 \%$ Nonidet P-40) containing phosphatase inhibitors (10 $\mathrm{mmol} / \mathrm{L} \mathrm{NaF}, 1 \mathrm{mmol} / \mathrm{L} \mathrm{Na}_{3} \mathrm{VO}_{4}$ and $50 \mathrm{mmol} / \mathrm{L}$ $\beta$-glycerophosphate) and protease inhibitors $(20 \mu \mathrm{g} / \mathrm{mL}$ leupeptin, $10 \mu \mathrm{g} / \mathrm{mL}$ pepstatin $\mathrm{A}$ and $4 \mu \mathrm{g} / \mathrm{mL}$ aprotinin). Debris was sedimented by centrifugation for 10 $\min$ at $14000 \times g$, and the protein concentration of the supernatant was determined using a Bio-rad protein de- tection assay kit. Proteins in the total cell lysate $(40 \mu \mathrm{g}$ of protein) were separated by $10 \%$ sodium dodecyl sulfate polyacrylamide gel electrophoresis (SDS/PAGE) and electrotransferred to a polyvinylidene difluoride membrane (Immobilon-P membrane; Millipore, Bedford, MA). After blocking the membranes in a solution of $5 \%$ skim milk and $0.1 \%$ Tween-20 in PBS, membrane-bound proteins were probed with primary antibodies against S100A4 (1:100) and MMP-13 (1:200). The membrane was washed and then incubated with horseradish peroxidase-conjugated secondary antibodies for $30 \mathrm{~min}$. Antibody-bound protein bands were detected using enhanced chemiluminescence reagents (Amersham Pharmacia Biotech, Piscataway, NJ) and visualized by autoradiography with Kodak X-Omat Blue film (Perkin Elmer Life Sciences, Boston, MA).

RT-PCR. Total RNA was isolated from the transfected cells using the Qiagen RNeasy kit (Qiagen, Inc., Valencia, CA) according to the manufacturer's protocol, and the OneStep RT-PCR kit (Qiagen) was used for detecting mRNA expression of S100A4 and MMP13. First-strand cDNA was prepared using Omniscript and Sensiscript reverse transcriptases at $50^{\circ} \mathrm{C}$ for 30 min. PCR amplification was performed under the following conditions: $95^{\circ} \mathrm{C}$ for $15 \mathrm{~min}$, followed by $35 \mathrm{cy}-$ cles at $94^{\circ} \mathrm{C}$ for $1 \mathrm{~min}, 56^{\circ} \mathrm{C}$ for $1 \mathrm{~min}$, and $72^{\circ} \mathrm{C}$ for $1 \mathrm{~min}$. The final extension was completed at $72^{\circ} \mathrm{C}$ for $10 \mathrm{~min}$. The primers used are shown below: S100A4 forward, 5'-CAGATCCTGACTGCTGCCATGGCG-3'; S100A4 reverse, 5'-ACGTGTCTGAAGGAGCCATGGTGG-3'; MMP-13 forward, 5'-CTATCCTGGCCACCTTCTTC-3'; MMP-13-reverse, 5'-GGGACCAT'T'TGA GTGTTCTAGG-3'; GAPDH-forward, 5'-CCACCCATGGCAAATTCCATCGCA-3'; GAPDH reverse, 5'TCTA GACGGCAGGTGAGGTCCACC-3'.

Gelatin zymography. An equal number of cells $\left(1 \times 10^{6}\right)$ was transfected with the S100A4 siRNA and pcDNA3.1-S100A4 plasmids, and after 24-48 h, the conditioned media were harvested, concentrated, and electrophoresed $(10 \mu \mathrm{g}$ of protein) under nonreducing conditions. The gelatinolytic activity of MMP-13 was determined with a zymography kit (Invitrogen) according to the manufacturer's protocol.

Cell motility and invasion assay. To assess the motility and invasion of MDA-231 cells, the upper chambers (8 $\mu \mathrm{m}$ pore size) of transwells (Costar) were coated with collagen at $4^{\circ} \mathrm{C}$; Matrigel $(0.5 \mu \mathrm{g}$; Collaborative Research) diluted with cold water was then dried onto each filter overnight at room temperature. Transwells were washed with PBS and cells transfected with the pcDNA3.1S100A4 plasmid for $36 \mathrm{~h}$ or the S100A4 siRNA plasmid for $48 \mathrm{~h}$ were added to the upper chamber using serumfree DMEM/bovine serum albumin. LPA was added to the lower chamber as a chemoattractant. The chambers were incubated for $2 \mathrm{~h}$ at $37^{\circ} \mathrm{C}$ in the presence of $10 \%$ $\mathrm{CO}_{2}$. The cells that attached to the bottom side of the membrane were stained and counted using crystal violet. Assays were performed in triplicate and repeated several times.

In vitro angiogenesis assay (Chicken embryo chorioallantoic membrane assay). Fertilized white Leghorn hen eggs were incubated in a humidified chamber at $37.8^{\circ} \mathrm{C}$ and $67 \%$ humidity. At day 3 of development, a window was cut into the egg shell and sealed again with adhesive plaster. The eggs were further incubated for 6 days. At 9 days, the window was opened and the chorioallantoic membranes (CAMs) of the chicken embryos were transduced with supernatant of MDA-231 cells [after transfection with pcDNA3.1-S100A4 plasmid 


\begin{tabular}{lllllllllll}
\hline \multicolumn{3}{c}{ S100A4 } & \multicolumn{7}{c}{ MMP-13 } \\
\hline Node Status & $\mathrm{n}$ & Negative & Positive & $\mathrm{X}^{2}$ & $\mathrm{P}$ & Negative & Positive & $\mathrm{X}^{2}$ & $\mathrm{P}$ & \\
Node+ & 50 & $11(22 \%)$ & $39(78 \%)$ & 5.17 & 0.003 & $9(18 \%)$ & $41(82 \%)$ & 4.83 & 0.008 \\
Node- & 50 & $29(58 \%)$ & $21(42 \%)$ & & & $33(66 \%)$ & $17(34 \%)$ & \\
\hline
\end{tabular}

Table 1. Relationship between S100A4 and MMP-13 expression and node status

was used for further studies. MDA-231 cells transfected with the pcDNA3.1-S100A4 plasmid showed significantly increased S100A4 levels compared with vector control-transfected cells (Fig. 2C).

(24 h) or S100A4 siRNA plasmid (48 h)]. Eggs were returned to the incubator for four additional days. At 13 days, the eggs were opened and the CAM with the Thermanox $^{\mathrm{TM}}$ ring was analyzed and photographed under a stereo microscope fitted with a digital camera and flexible cold light (Olympus SZ51, Olympus E410). Blood vessels were counted inside the ring area $\left(20 \mathrm{~mm}^{2}\right)$. The allantoic vascular plexus was subclassified into large vessels (diameter $>50 \mu \mathrm{m}$ ) and microvessels (diameter $<50$ $\mu \mathrm{m})$.

In vivo experimental metastasis assays. MDA-231 cells $\left(1 \times 10^{6}\right)$ transfected with S100A4 siRNA for $48 \mathrm{~h}$ or stably transfected with the pcDNA3.1-S100A4 plasmid were injected into the tail vein of 6- to 8-week-old mice $(n=6)$. After 21 days, the mice were sacrificed, and the lungs were fixed in Bouin's solution. Lung tumors were analyzed first by obtaining a surface tumor count, and then by assessing tumor area in histologic sections from multiple depths throughout the lungs.

Statistical analysis. All statistical analyses were performed using SPSS13.0 software. The results were expressed as means \pm S.D. Differences between the groups were assessed by the Student's t-test or Pearson's chisquare test $\left(\chi^{2}\right)$ and $P<0.05$ was considered to indicate statistical significance.

\section{RESULTS}

\section{Relationship between S100A4 and MMP-13 expression and node status}

S100A4 and MMP-13 protein expression was detected in the cytoplasm of $60 \%$ and $58 \%$ of breast cancer specimens, respectively (Fig. 1). Increased S100A4 and MMP-13 expression levels were correlated with lymph node metastases $(P<0.01$, all) (Table 1$)$, and there was a significant correlation between the expression levels of S100A4 and MMP-13 in breast cancer cells $(P=0.001)$ (Table 2). These results indicate that metastasis from breast cancer is associated with significantly increased expression of S100A4 and MMP13.

\section{siRNA mediated knock-down of S100A4 expression in MDA-MB-231 cell}

S100A4 siRNA transfection of cells decreased the levels of S100A4 protein (Fig. 2A) and mRNA (Fig. 2B) in a dose-dependent manner as shown by western blotting and RT-PCR. Non-silencing siRNAs had no effect on the S100A4 protein level (data not shown). These data confirmed the siRNA mediated knock-down of S100A4 expression. Based on the lowest levels of S100A4 expression, a $48 \mathrm{~h}$ siRNA transfection was used in all subsequent experiments.

\section{S100A4 overexpression in MDA-MB-231 cells}

Overexpression of S100A4 was confirmed by western blotting $36 \mathrm{~h}$ after transfection. Based on the highest levels of S100A4 expression, a $36 \mathrm{~h}$ transfection

\section{Effect of S100A4 on motility, invasion and angiogenesis of MDA-MB-231 cells}

The S100A4 gene has been reported to confer invasive characteristics on various cancer cells. We therefore examined the effect of S100A4 gene suppression or overexpression on the motility, invasion and angiogenesis of the highly invasive and metastatic MDA-231 cell line using in vitro chemoinvasion and chicken embryo CAM assays. As shown in Figure 2D, suppression of S100A4 expression using siRNA effectively blocked MDA-231 cell motility and invasion, whereas S100A4 overexpression promoted MDA-231 cell motility and invasion, suggesting that S100A4 plays an essential role in metastasis. The effect of S100A4 on angiogenesis was assessed using an in vitro CAM assay. The supernatant of S100A4-siRNA or S100A4 cDNA-transfected MDA-231 cells was added to the CAMs of chicken embryos and the total tube area was quantified. S100A4-siRNA-transfected MDA-231 cell supernatants effectively decreased the total tube area, whereas S100A4 cDNA-transfected MDA-231 cell supernatants increased the total tube area (Fig. 2E).

\section{S100A4 regulates MMP-13 expression and its enzymatic activity}

The effect of S100A4 silencing or overexpression on the expression and activity of MMP-13 was assessed. S100A4 siRNA transfection significantly decreased MMP-13 mRNA (Fig. 3A) and protein (Fig. 3B) levels, whereas S100A4 overexpression significantly increased MMP-13 mRNA (Fig. 3A) and protein (Fig. 3B) levels in MDA-231 cells. Transfection with mock vector had no effect. The effect of S100A4 knockdown or overexpression on the activity of MMP-13 was examined by gelatin zymography. S100A4 gene silencing significantly
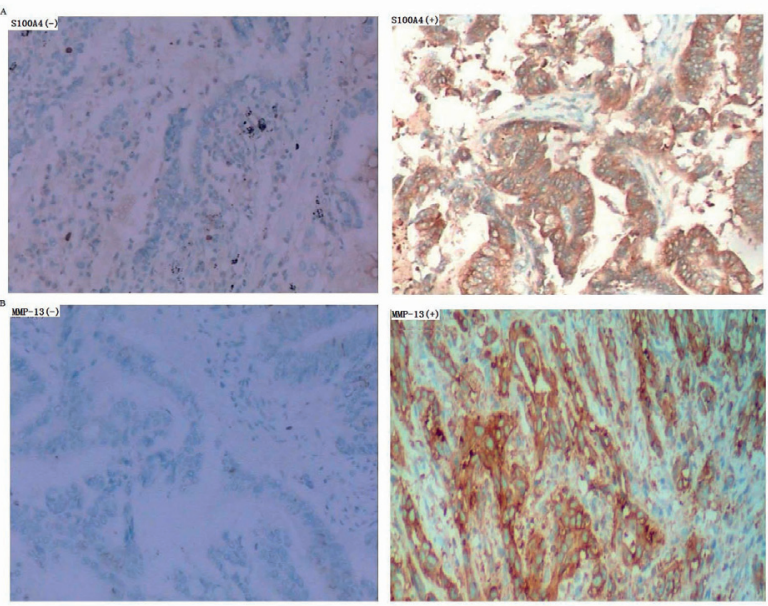

Figure.1. Representative immunohistochemistry of an infiltrating ductal carcinoma.

(A) S100A4; (B) MMP-13. The brown stain represents the indicated antigen and the nuclei are counterstained in blue. $\times 100$. 
Table 2. Relationship between S100A4 and MMP-13 expression levels

\begin{tabular}{llllll}
\hline \multicolumn{5}{c}{ MMP-13 expression } \\
\hline S100A4 expression & No. & Positive & Negative & $X^{2}$ & P \\
\hline Positive & $60(60 \%)$ & $46(76.7 \%)$ & $14(23.3 \%)$ & & \\
Negative & $40(40 \%)$ & $12(30 \%)$ & $28(70 \%)$ & 6.75 & 0.001
\end{tabular}

had a significant effect on the development of lung metastases, causing a 50\% increase in the number of surface tumors compared to the controls (S100A4 cDNA transfected mice median tumor number $=109.4$; Fig. 5B). To further examine the metastatic lesions, the lungs were sectioned at different depths and the specimens were assessed morphometrically to determine the percent of lung parenchyma occupied by tumor le-

decreased MMP-13 enzymatic activity, and S100A4 overexpression significantly increased MMP-13 enzymatic activity in MDA-231 cells (Fig. 3C). These results indicated that the S100A4-mediated decrease or increase of MMP-13 mRNA and protein levels led to the inhibition or enhancement of MMP-13 enzymatic activity $(P<0.05)$.

\section{S100A4 overexpression promotes metastasis through MMP-13 upregulation}

To determine whether the effect of S100A4 on promoting invasion and angiogenesis in MDA-231 cells is mediated by MMP-13, cells were pretreated with 0.1 units of a neutralizing MMP-13 antibody for $12 \mathrm{~h}$ before transient transfection with S100A4 cDNA (4 $\mu \mathrm{M})$ for $36 \mathrm{~h}$. The results showed that the enhanced invasion and angiogenesis caused by S100A4 overexpression and MMP-13 protein and mRNA upregulation (Fig. 3A and B) were suppressed by MMP-13 neutralization, which inhibited the upregulation of MMP-13 by S100A4 cDNA transfection (data not shown) and the invasive phenotype of MDA-231 cells (Fig. 4A and B).

\section{S100A4 regulates the metastatic potential of MDA- MB-231 cells}

The effect of S100A4 on metastasis was examined in vivo using a mouse tumor model. Mice transfected with S100A4 siRNA showed a $60 \%$ reduction of the number of surface tumors compared to control mice $(22.7$ vs. 58.6; Fig. 5A). In contrast, overexpression of S100A4 sions. Similar to the surface count results, a significant reduction in tumor burden was observed in the lungs of S100A4 siRNA transfected mice compared to littermate controls. The $73 \%$ reduction in total tumor area in the lungs correlated well with the $60 \%$ reduction in the number of surface tumor lesions (Fig. 5C). In contrast, S100A4 cDNA transfected mice showed a significant increase in tumor burden in the lungs compared to littermate controls. The $50 \%$ increase in total tumor area in the lungs correlated well with the $50 \%$ increase in the number of surface tumor lesions (Fig. 5D).

\section{DISCUSSION}

Metastasis is generally defined as the spread of malignant cells from the primary tumor to distant sites through the circulation. Studies in rodents have provided evidence supporting direct involvement of S100A4 in tumor progression and metastasis. The role of S100A4 in cancer has been examined extensively in breast cancer models, in which overexpression of S100A4 in nonmetastatic mammary tumor cells confers a metastatic phenotype (Davies et al., 1993; Grigorian et al., 1996). Transgenic mice overexpressing S100A4 in the mammary epithelium are phenotypically indistinguishable from wildtype mice (Ambartsumian et al., 1996), demonstrating that S100A4 itself is not tumorigenic. However, transgenic mouse models of breast cancer have shown that S100A4 expression correlates with metastasis. The link
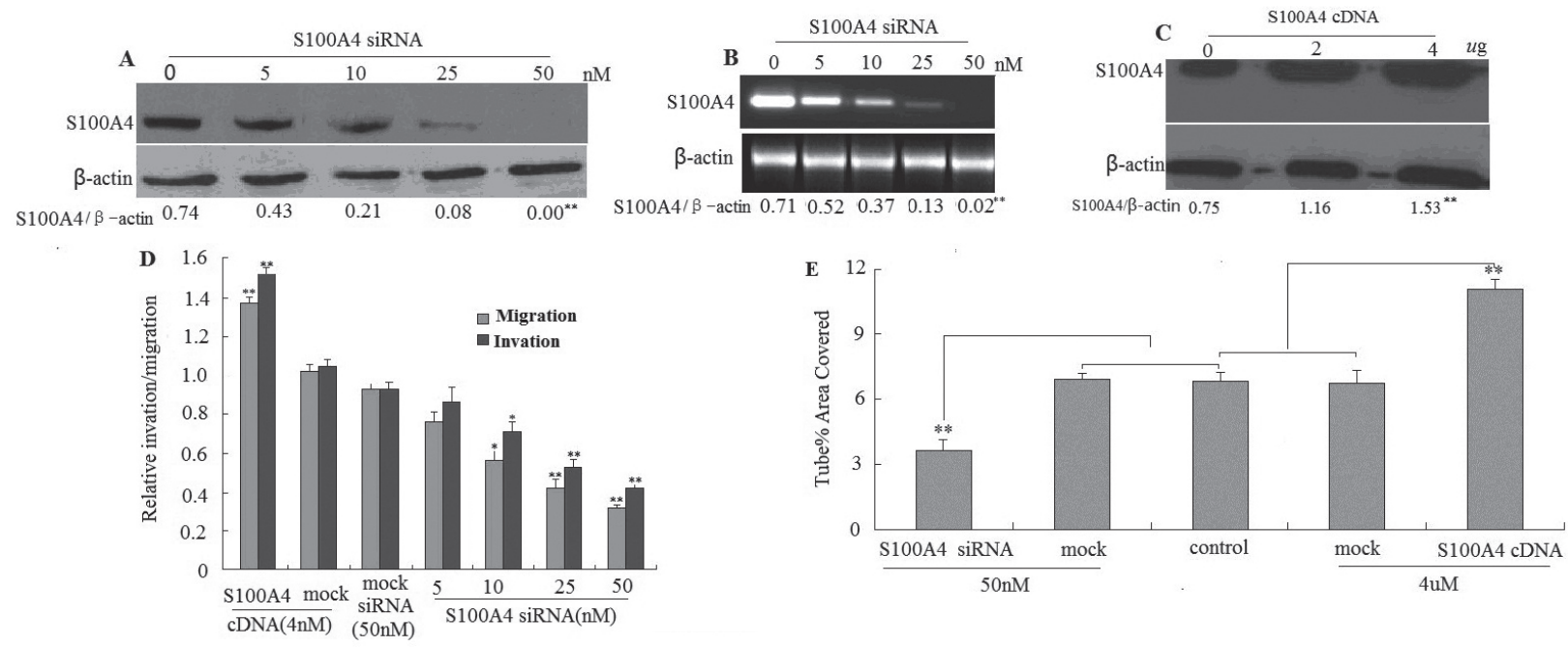

Figure 2. siRNA-mediated knockdown of S100A4 expression in MDA-MB-231 cells

(A and B) Representative images showing S100A4 protein and mRNA expression levels in S100A4-siRNA transfected cells as determined by western blotting (A) and RT-PCR (B). (C) Representative images showing S100A4 protein levels in S100A4 cDNA-transfected cells as determined by western blotting. (D) The motility and invasion ability of MDA-231 cells was assessed using a transwell cell motility assay as described in the Materials and Methods section. Each bar represents the mean \pm S.E. Statistical analyses were performed using the Student's t-test. ${ }^{*} P<0.01$ or ${ }^{*} P<0.05$ compared with the controls. All experiments were repeated three times with similar results. (E) The supernatant of MDA-231 cells transfected with S100A4 siRNA inhibited angiogenesis, and the supernatant of MDA-231 cells transfected with S100A4 CDNA enhanced angiogenesis in the CAMs of hen embryos with a statistically significant decrease or increase in the percentage of tube area covered compared with untreated groups $\left({ }^{*} P<0.01\right)$. 
A

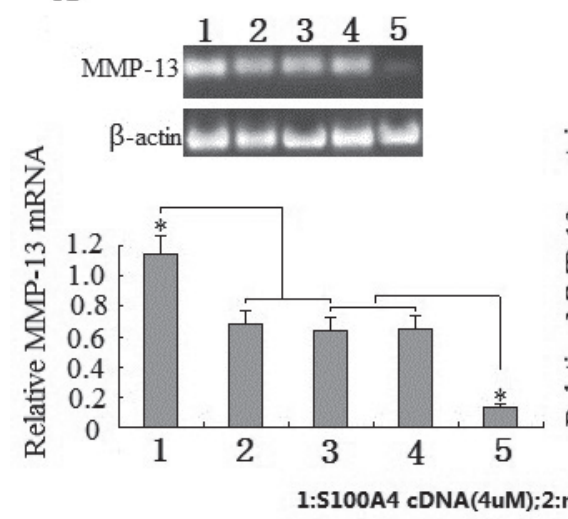

$\mathbf{B}$

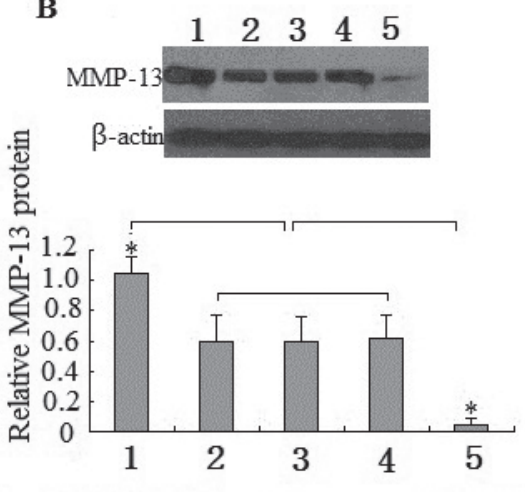

C $\quad \begin{array}{lllll}1 & 2 & 3 & 4 & 5\end{array}$ Active $\quad-\ldots \ldots \ldots$ MMP-13

$\beta$-actin $=--$

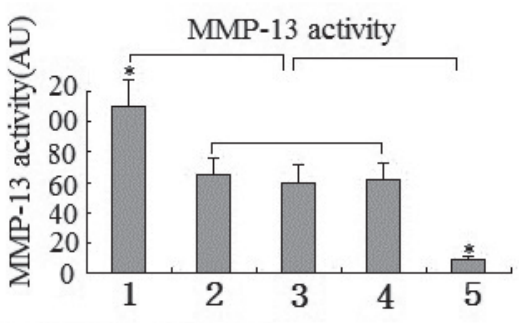

Figure 3. Effect of S100A4 gene knockdown or overexpression on the expression and activity of MMP-13

(A) Effect of S100A4 overexpression or silencing on MMP-13 mRNA levels in MDA-231 cells assessed by RT-PCR. (B), Effect of S100A4 overexpression or silencing on MMP-13 protein levels in MDA-231 cells assessed by western blotting. (C) Effect of S100A4 overexpression or silencing on MMP-13 enzymatic activity in MDA-231 cells assessed by gelatin zymography. All experiments were repeated three times with similar results.

between S100A4 and metastasis is further supported by knockdown experiments, as inhibition of S100A4 expression by antisense or anti-ribozyme techniques suppresses the metastatic capacity of S100A4-expressing tumor cells in animal models of lung carcinoma (Maelandsmo et al., 1996). However, the exact mechanisms underlying the metastasis-promoting effects of S100A4 are less well defined.

As a member of the $\mathrm{S} 100$ family of $\mathrm{Ca}^{2+}$ binding proteins, S100A4 functions intra- and extracellularly. When released into the extracellular space, it promotes the differentiation of neurons and osteoclasts (Novitskaya et al., 2000; Duarte et al., 2003). Furthermore, S100A4 acts as an angiogenic factor by stimulating the motility of endothelial cells (Ambartsumian et al., 2001). It has been shown that S100A4 is released by tumor and normal cells (Ambartsumian et al., 2001; Duarte et al., 2003). Taken together, these findings indicate that extracellular S100A4 may generate a microenvironment that promotes invasion and motility of both endothelial and tumor cells, and therefore facilitates the dissemination of tumor cells in the organism.

Our results showed that S100A4 overexpression was associated with lymph node metastasis from breast cancer. Furthermore, S100A4 expression was significantly correlated with the levels and activity of MMP-13. These results indicate an association between breast cancer metastasis and increased levels of S100A4 and MMP13, and suggest that S100A4 may promote metastasis through MMP13 upregulation. We also showed that S100A4 overexpression increased the invasiveness of MDA231 cells and stimulated angiogenesis, whereas S100A4 knockdown reversed this effect in vitro. Furthermore, downregulation of S100A4 expression suppressed lung metastasis in a transgenic mouse model, whereas overexpression of the protein had the opposite effect.

The ability to migrate is a prerequisite for a cancer cell to escape the primary tumor and enter the circulation. However, to travel through the surrounding stroma, these locally invading cells must be able to proteolytically degrade extracellular matrix components. Matrix metalloproteinases (MMPs) play an essential role in this process.

MMP-13 (collagenase-3) was originally cloned from a human breast tumor cDNA library (Freije et al., 1994), and has since been shown to be elevated in a variety of cancers (Acuff et al., 2006). MMP-13 was reported to affect the levels of a functionally diverse range of proteins, including those known to be involved in the promotion of tumor growth, angiogenesis and metastasis (Neutzner et al., 2007). An association between S100A4 expression,
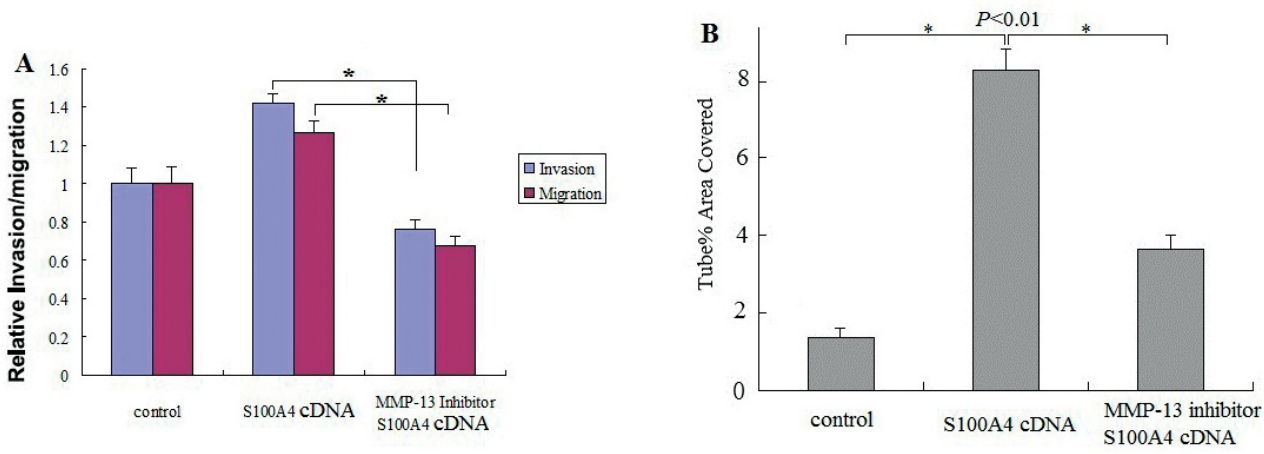

Figure 4. MMP-13 inhibition suppresses S100A4-induced invasion and angiogenesis

(A) Representative histogram showing the invasive capability of MDA-231 cells transfected with S100A4 CDNA and treated with an MMP13 inhibitor assessed in a chemoinvasion chamber. (B) Representative histogram showing the tube percent area covered in MDA-231 cells transfected with S100A4 CDNA and treated with an MMP-13 inhibitor. Each bar represents the mean \pm S.E.; ${ }^{*} P<0.01$. All experiments were repeated three times with similar results. 

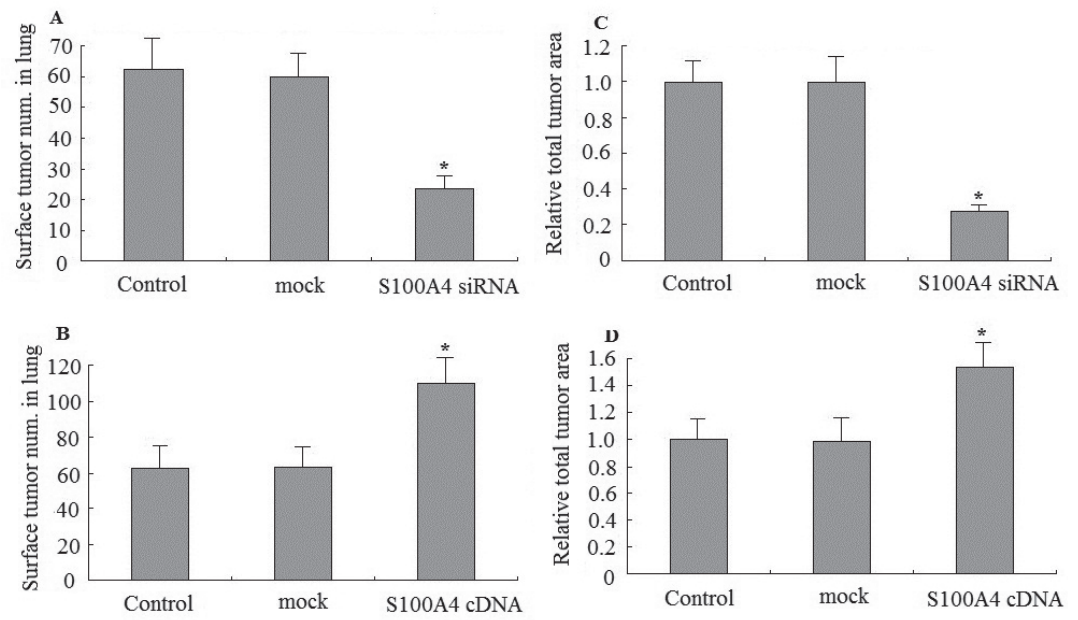

Figure.5. Effect of S100A4 on lung metastasis

( $A$ and $\mathbf{B}$ ) Representative histograms showing the surface tumor number in the S100A4 siRNA and S100A4 CDNA groups. (C and D) Representative histograms showing the total tumor area in the lungs of the S100A4 siRNA and S100A4 cDNA groups. Each bar represents mean \pm S.E.; ${ }^{*} P<0.01$. All experiments were repeated three times with similar results.

MMP-13 activity and metastatic potential of human tumor cells has been reported (Schmidt-Hansen et al., 2004).

In the present study, S100A4 was shown to stimulate invasion and metastasis, promote angiogenesis, and upregulate MMP-13. Conversely, S100A4 silencing suppressed invasion and metastasis, inhibited angiogenesis and downregulated MMP-13. The S100A4-induced stimulation of invasiveness and metastasis was attenuated by treatment with anti-MMP-13, a specific inhibitor of MMP-13 activity. Taken together, our findings suggest that the metastasis and angiogenesis promoting effect of S100A4 may be mediated by the regulation of MMP-13.

Considering the role of S100A4 in tumor progression, our findings that its presence in the extracellular space induces the expression of MMP-13 offers a new mechanistic explanation for its role as a metastasis stimulating protein.

\section{REFERENCES}

Ambartsumian N, Klingelhöfer J, Grigorian M, Christensen C, Kriajevska M, Tulchinsky E, Georgiev G, Berezin V, Bock E, Rygaard J, Cao R, Cao Y, Lukanidin E (2001) The metastasis-associated Mts1(S100A4) protein could act as an angiogenic factor. Oncogene 20: 4685-4695.

Ambartsumian NS, Grigorian MS, Larsen IF, Karlstrøm O, Sidenius N, Rygaard J, Georgiev G, Lukanidin E (1996) Metastasis of mammary carcinomas in GRS/A hybrid mice transgenic for the mts1 gene. Oncogene 13: 1621-1630.

Acuff HB, Carter KJ, Fingleton B, Gorden DL, Matrisian LM (2006) Matrix metalloproteinase- 9 from bone marrow-derived cells contributes to survival but not growth of tumor cells in the lung microenvironment. Cancer Res 66: 259-266.

Duarte WR, Shibata T, Takenaga K, Takahashi E, Kubota K, Ohya K, Ishikawa I, Yamauchi M, Kasugai S (2003) S100A4: a novel negative regulator of mineralization and osteoblast differentiation. $J$ Bone Miner Res 18: 493-501.

Davies BR, Davies MP, Gibbs FE, Barraclough R, Rudland PS (1993) Induction of the metastatic phenotype by transfection of a benign rat mammary epithelial cell line with the gene for $\mathrm{p} 9 \mathrm{Ka}$, a rat calcium-binding protein, but not with the oncogene EJ-ras-1. Oncogene 8: $999-1008$

Ford HL, Zain SB (1995) Interaction of metastasis associated Mts1 protein with nonmuscle myosin. Oncogene 10: 1597-1605.

Freije JM, Díez-Itza I, Balbín M, Sánchez LM, Blasco R, Tolivia J, López-Otín C (1994) Molecular cloning and expression of collagenase-3, a novel human matrix metalloproteinase produced by breast carcinomas. I Biol Chem 269: 16766-1673.

Grigorian M, Ambartsumian N, Lykkesfeldt AE, Bastholm L, Elling F, Georgiev G, Lukanidin E (1996) Effect of mts1 (S100A4) expres- sion on the progression of human breast cancer cells. Int J Cancer 67: 831-841.

Garrett SC, Varney KM, Weber DJ, Bresnick AR (2006) S100A4, a mediator of metastasis. J Biol Chem 281: 677-680.

Ismail NI, Kaur G, Hashim H, Hassan MS (2010) S100A4 overexpression proves to be independent marker for breast cancer progression. Cancer Cell Int 8: 12.

Jenkinson SR, Barraclough R, West CR, Rudland PS (2004) S100A4 regulates cell motility and invasion in an in vitro model for breast cancer metastasis. Br J Cancer 90: 253-262.

Klingelhöfer J, Ambartsumian NS, Lukanidin EM (1997) Expression of the metastasis-associated mts1 gene during mouse development. Dev Dyn 210: 87-95.

Levett D, Flecknell PA, Rudland PS, Barraclough R, Neal DE, Mellon JK, Davies BR (2002) Transfection of S100A4 produces metastatic variants of an orthotopic model of bladder cancer. Am J Pathol 160: 693-700.

Liu X, Li F, Sun SQ, Thangavel M, Kaminsky J, Balazs L, Ostrom RS (2010) Fibroblast-specific expression of AC6 enhances beta-adrenergic and prostacyclin signaling and blunts bleomycin-induced pulmonary fibrosis. Am J Physiol Lung Cell Mol Physiol 298: L819-L829.

Lloyd BH, Platt-Higgins A, Rudland PS, Barraclough R (1998) Human S100A4 (p9Ka) induces the metastatic phenotype upon benign tumour cells. Oncogene 17: 465-473.

Malashkevich VN, Varney KM, Garrett SC, Wilder PT, Knight D,Charpentier TH, Ramagopal UA, Almo SC, Weber DJ, Bresnick AR (2008) Structure of Ca2_-bound S100A4 and its interaction with peptides derived from nonmuscle myosin-IIA. Biochemistry 47: 5111-5126.

Maelandsmo GM, Hovig E, Skrede M, Engebraaten O, Flørenes VA, Myklebost O, Grigorian M, Lukanidin E, Scanlon KJ, Fodstad O (1996) Reversal of the in vivo metastatic phenotype of human tumor cells by an anti-CAPL (mts1) ribozyme. Cancer Res 56: 5490-5498.

Matsuura I, Lai CY, Chiang KN (2010) Functional interaction between Smad3 and S100A4 (metastatin-1) for TGF- $\beta$-mediated cancer cell invasiveness. Biochem J 426: 327-335.

McKay JA, Douglas JJ, Ross VG (2002) Analysis of key cell cycle checkpoint proteins in colorectal tumours. J Pathol 196: 386-393.

Neutzner M, Lopez T, Feng X, Bergmann-Leitner ES, Leitner WW, Udey MC (2007) MFG-E8/lactadherin promotes tumor growth in an angiogenesis-dependent transgenic mouse model of multistage carcinogenesis. Cancer Res 67: 6777-6785.

Novitskaya V, Grigorian M, Kriajevska M, Tarabykina S, Bronstein I, Berezin V, Bock E, Lukanidin E (2000) Oligomeric forms of the metastasis-related Mts1 (S100A4) protein stimulate neuronal differentiation in cultures of rat hippocampal neurons. J Biol Chem 275: 41278-41286.

Rudland PS, Platt-Higgins A, Renshaw C, West CR, Winstanley JH, Robertson L, Barraclough R (2000) Prognostic significance of the metastasis-inducing protein $\mathrm{S} 100 \mathrm{~A} 4 \mathrm{(p} 9 \mathrm{Ka})$ in human breast cancer. Cancer Res 60: 1595-1603.

Schmidt-Hansen B, Ornås D, Grigorian M, Klingelhöfer J, Tulchinsky E, Lukanidin E, Ambartsumian N (2004) Extracellular S100A4(mts1) stimulates invasive growth of mouse endothelial cells and modulates MMP-13 matrix metalloproteinase activity. Oncogene 23: 5487-5495.

Simpson PT, Shoker BS, Barraclough R, Halliwell N, Rudland PS, Sibson DR, Davies MP (2003) Examination of tumour histopathology and gene expression in a neu/S100A4 transgenic model of metastatic breast cancer. Int I Exp Pathol 84: 173-184.

Schmidt-Hansen B, Dorte O, Grigorian M, Klingelho J, Tulchinsky E, Lukanidin E, Ambartsumian N (2004) Extracellular S100A4(mts1) stimulates invasive growth of mouse endothelial cells and modulates MMP-13 matrix metalloproteinase activity. Oncogene 23: 5487-5495.

Wang G, Platt-Higgins A, Carroll J, de Silva Rudland S, Winstanley J, Barraclough R, Rudland PS (2006) Induction of metastasis by $\mathrm{S} 100 \mathrm{P}$ in a rat mammary model and its association with poor survival of breast cancer patients. Cancer Res 66: 1199-1207.

Zhang B, Cao X, Liu Y, Cao W, Zhang F, Zhang S, Li H, Ning L, Fu L, Niu Y, Niu R, Sun B, Hao X (2008) Tumor-derived matrix metalloproteinase-13 (MMP-13) correlates with poor prognoses of invasive breast cancer. BMC Cancer 8: 83-90. 